\title{
Improving a newly adapted teaching and learning approach: Collaborative Learning Cases using an action research
}

\author{
Shuh Shing Lee', Shing Chuan Hooi ${ }^{2}$, Terry Pan ${ }^{3}$, Chong Hui Ann Fong ${ }^{1}$ and Dujeepa D. Samarasekera \\ ${ }^{1}$ Centre for Medical Education and ${ }^{2}$ Department of Physiology, Yong Loo Lin School of Medicine, National \\ University of Singapore and ${ }^{3}$ Department of Anaesthesiology, National University Health, National University \\ Health System, Singapore
}

Purpose: Although medical curricula are now better structured for integration of biomedical sciences and clinical training, most teaching and learning activities still follow the older teacher-centric discipline-specific formats. A newer pedagogical approach, known as Collaborative Learning Cases (CLCS), was adopted in the medical school to facilitate integration and collaborative learning. Before incorporating CLCs into the curriculum of year 1 students, two pilot runs using the action research method was carried out to improve the design of CLCs.

Methods: We employed the four-phase Kemmis and McTaggart's action research spiral in two cycles to improve the design of CLCs. A class of 300 first-year medical students (for both cycles), 11 tutors (first cycle), and 16 tutors (second cycle) were involved in this research. Data was collected using the 5-points Likert scale survey, open-ended questionnaire, and observation.

Results: From the data collected, we learned that more effort was required to train the tutors to understand the principles of CLCs and their role in the CLCs sessions. Although action research enables the faculty to improve the design of CLCs, finding the right technology tools to support collaboration and enhance learning during the CLCs remains a challenge.

Conclusion: The two cycles of action research was effective in helping us design a better learning environment during the CLCs by clarifying tutors' roles, improving group and time management, and meaningful use of technology.

Key Words: Teaching, Education, Curriculum, Learning, Students

\section{Introduction}

Feedback of student A: I learned basic medical sciences in year 1 and year 2. I found some of the subjects difficult to understand and overloaded with facts. Due to time constraints and the competing demands of many subjects, I decided to rehearse and memorise the lecture notes and model answers handed down from my seniors. I knew I will be rewarded by reproducing well- rehearsed answer. However, when I progressed to my clinical years, I found that not only have I forgotten the basic medical science content, I also found it difficult to relate the knowledge that I have to explain what happens to patients.

The above is a typical problem faced by students learning the biomedical sciences in the early years of medical school. After the publication of the Flexner report in 1910, medical education became more
Received: September 5, 2018 • Accepted: October 9, 2018

Corresponding Author: Dujeepa D. Samarasekera (https://orcid.org/0000-0002-6916-6741) Centre for Medical Education, Yong Loo Lin School of Medicine, National University of Singapor, Block MD11 \#05-10, Clinical Research Centre 10 Medical Drive, Singapore 117597 Tel: +65.65163760 Fax:+65.68721454 email: meddds@nus.edu.sg
Korean J Med Educ 2018 Dec; 30(4): 295-308.

https://doi.org/10.3946/kjme.2018.104

eISSN: 2005-7288

(C) The Korean Society of Medical Education. All rights reserved. This is an open-access article distributed under the terms of the Creative Commons Attribution Non-Commercial License (http:// creativecommons.org/licenses/by-nc/3.0/), which permits unrestricted non-commercial use, distribution, and reproduction in any medium, provided the original work is properly cited. 
streamlined and educational approaches were made more systematic by focusing on biomedical sciences in the early years and clinical learning in the later years of medical training [1]. This further evolved into a more discipline-specific teaching in anatomy, physiology, biochemistry, pharmacology, and pathology in the early years of medical education. After completing the biomedical science years, medical students typically progress to clinical training in hospitals or family medicine or primary care settings. This division between the biomedical sciences and clinical training has widened over the years and has led to memorisation and an exam-centric approach to learning biomedical science concepts and constructs. Students also report a poor foundation in the biomedical sciences and the inability to apply basic concepts to clinical practice [2], leading to a poor understanding of clinical medicine and practice. The major weaknesses identified in this approach include poor integration, content overload without sufficient time to critically evaluate and discuss the biomedical content as well as teacher-centric, discipline-specific, and mostly didactic teaching pedagogies [2].

Several learning pedagogies have arisen in an attempt to foster better integration and application of the biomedical sciences content, including problem-based learning (PBL), team-based learning, and case-based learning (CBL) [3-5]. PBL was introduced as a teaching- learning method in Yong Loo Lin School of Medicine, National University of Singapore (NUS Medicine) in 1997 and modified to 'case based learning' sessions in 2008 with a focus on application of biomedial science content that has been learned to clinical scenarios [6]. However, as pointed out by Kirschner et al. [7], the school found that the pedagogical approach overwhelmed the novice learners who lack of proper schema to work with under minimal guidance and 'summary' sessions, which were mainly didactic, were needed to fill in the gaps.

As part of the ongoing continuous quality improvement process, NUS Medicine reviewed the curriculum in 2014, including the CBLs, in order to integrate more effective learning pedagogies into the design of the learning events. Taking into consideration the increasing number of medical students and the importance of promoting self-directed and deeper learning, the school took a systems design approach in reviewing and aligning all teaching events to optimise learning. Lectures, tutorials, simulation, and practical sessions were aligned with 'capstone' sessions. These 'capstone' sessions were a modification of the case-based learning sessions. The key pedagogical principles involved in the design of these 'capstone session' were (1) the need to scaffold knowledge in a way that will empower novice students to apply knowledge to understand clinical problems and (2)

Fig. 1. CLCs Serve as a Capstone for All Teaching Modalities in Yong Loo Lin School of Medicine, National University of Singapore

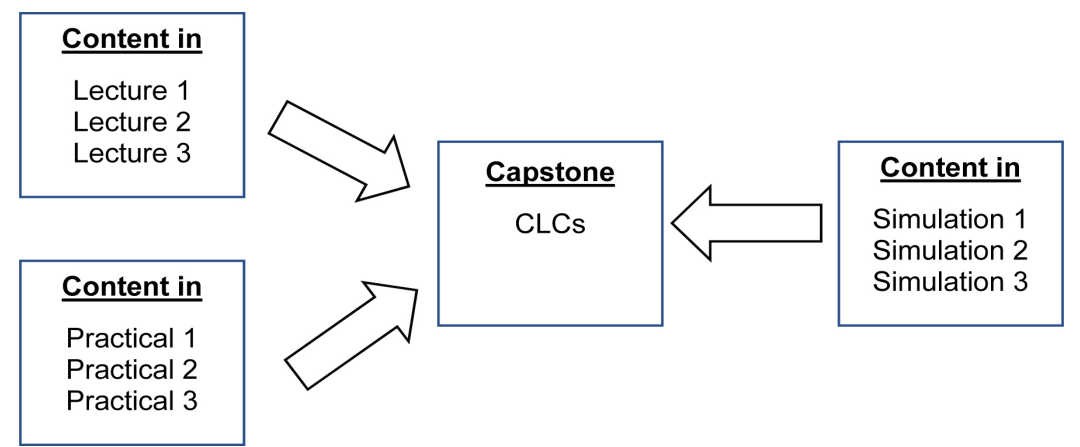

CLCs: Collaborative Learning Cases. 
for students to actively construct their own knowledge base in the biomedical sciences through a shared dialogic space with peers, guided by facilitators, thereby encouraging self-directed learning. Both the principles encourage active learning by the student, and the development of other important outcomes, apart from knowledge aquisition, including teamwork and communication skills, mutual respect, and the use of information technology (IT). NUS Medicine named these capstone sessions (Fig. 1) as Collaborative Learning Cases (CLCs). The CLCs adapted a Collaborative Pedagogical Model employed earlier by the Faculty of Education, University of Cambridge [8,9].

Before carrying out the actual CLC sessions, we conducted two pilot runs using an action research methodology. This was done to improve the design of the learning environment for the implementation of the CLCs, including the use of technology. Studies have highlighted the difficulty of optimising the use of technology in learning environments [10-13]. This action research will help educators find meaningful technological tools to support student learning during the CLCs.

\section{Methods}

A class of 300 first-year medical students (for first and second cycles), 11 tutors (first cycle), and 16 tutors (second cycle) were involved in this research. We employed the four-phase Kemmis and McTaggart [14] action research spiral (Fig. 2) in the two cycles to improve the CLCs approach [13].

Plan: improvements were planned

Act: improvements were implemented

Observe: observation data were collected, analysed and interpreted

Reflect: problems and opportunities for improvement were identified

An action research was employed by the researchers, as it generated information for improving practices by solving the problems that arose during the implementation. The findings are situation and context-specific.

Implied informed consent was obtained from all participants. Participant identity is anonymised to ensure the confidentiality of this research.

Fig. 2. The Overall CLCs Implementation Flow

\section{Pre-reading revision}

- Inform students at least 2 weeks before

- Activate prior knowledge

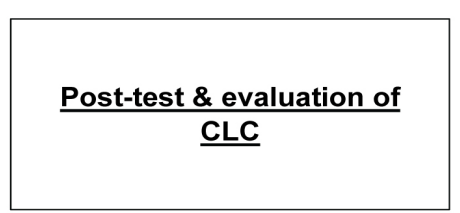

CLCs: Collaborative Learning Cases.

\section{Case revision}

- Solving a case with prompting questions

- Students discussion

- Tutor scaffolding

- Sharing and clarifying

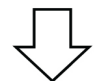

Summing up session

- Summarize learning key points

- Linking the key points with the case outcomes

- Clarifying further doubts and gaps 


\section{Planning and acting phase of collaborative learning cases}

The process of implementation, or acting phase in the action research cycle was not an easy task. Before implementing, several processes were performed: constructing cases, conducting case writers' training workshops, conducting workshop for tutors, and preparing the necessary technological tools. In this section, a more detailed planning phase will be discussed, followed by a description of the implementation (acting) of the CLCs.

During the planning phase, academic staff from different departments were recruited to form a CLCs committee. In alignment with the "Entrustable Professional Activities' of the medical programme and the necessary basic clinical knowledge in year 1, the committee decided on the essential cases. Table 1 shows the cases for year 1 .

All case writers were trained to write good quality cases. Case writing workshops were conducted for the academic staff to obtain feedback on reading materials and 'prompting questions' for students. Validation of the cases was carried out several rounds before consensus was achieved. The cases were pilot tested for further enhancement. Tutors conducting the CLCs sessions were also recruited and underwent two training sessions-one dealing with the pedagogical principles underlying the
CLCs and the other focusing on the content of the cases. The implementation (acting) of CLCs was based on the collaborative pedagogical model proposed by the Faculty of Education, University of Cambridge. CLCs emphasise the centrality of a shared dialogic space where the knowledge building derives from the interactions and co-construction within the dialogic space, guided by experts. Guiding questions around the case scenarios were designed to help students scaffold knowledge and reactivate prior learning. The success of a dialogic space requires teacher mediation, students' active participation, and classroom participation structures (tools such as IT, flip board, etc.). Based on this model, a few smaller groups (five to six students per group) were formed within a larger group (30-36 students) in one technologyequipped room. In total, five breakout rooms were utilised to accommodate 150 first-year medical students. These sessions were carried out twice per day to accommodate 300 students (one in the morning and one in the afternoon). Each large group (30-36 students) was facilitated by a facilitator using a clinical case. To harness collaboration and allow a streamlined presentation of a case study with questions flowing in a logical manner, the Educational Technology Team designed the CLCs as a web-based case using multiple technological tools such as a learning management system which is known as Integrated Virtual Learning Environment

Table 1. Collaborative Learning Cases for Yong Loo Lin School of Medicine, National University of Singapore Year 1

\begin{tabular}{rll}
\hline No. & \multicolumn{1}{c}{ Systems } & \\
\hline 1 & Haematology & Easy bruising, bleeding disorders \\
2 & Respiratory & Shortness of breath, cyanosis, asthma \\
3 & Cardiovascular & Chest pain, myocardiac infarction, ischemia \\
4 & Renal & Postural hypotension diarrhoea leading to fluid loss and electrolyte abnormality \\
5 & Gastroenterology & Abdominal distension: ascites or obstructions \\
6 & Endocrine & Diabetes mellitus and metabolic acidosis; renal failure, vascular complications \\
7 & Reproduction & Female pregnancy \\
8 & Multi systems & Septic shock, multi organ failure \\
9 & Multi systems & Jaundice: prehepatic \\
10 & Neurology & Limb weakness \\
\hline
\end{tabular}


Fig. 3. An Example of Web-based Case Using Video to Deliver the Case in Integrated Virtual Learning Environment

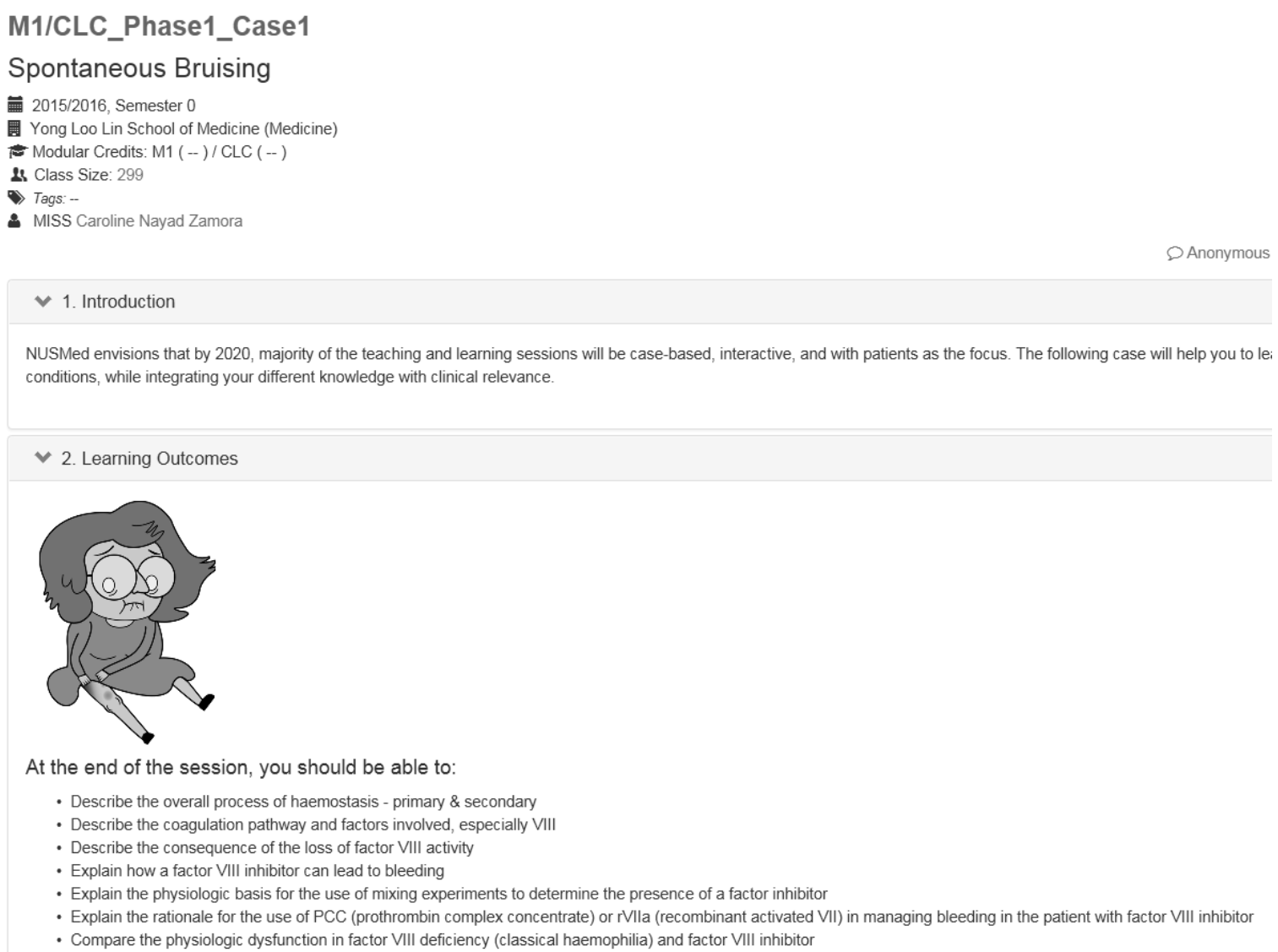

(IVLE), a document sharing platform 'Google Doc' and a discussion platform 'Padlet.' The clinical scenario was rolled out in a sequential manner and the students were actively engaged to answer the questions posted in each of the sections. The use of technology enables the cases to include links to useful websites, YouTube videos, library, and other relevant resources. An example of the web-based case using IVLE is shown in Fig. 3.

Students were given pre-reading materials 2 weeks prior to the session to activate their prior knowledge. The actual classroom case discussion was 2 hours in duration. During the in-class case discussion, students discussed the case and answered the prompting questions. This is to activate their prior knowledge and apply the newly learned knowledge in solving a case. The facilitator scaffolded when necessary and summarised the key learning points by linking them to the outcomes of the case and clarified any unresolved queries or gaps in knowledge.

At the end of the session, a post-test was administered to identify misconceptions or gaps amongst the students. The overall CLCs implementation flow is depicted in Fig. 2.

\section{Observation methods}

In the observation phase of the action research cycle, both quantitative and qualitative data collection methods were used to evaluate students' and tutors' experience of the implementation of CLCs. To date, two pilot runs of CLCs have been executed. In each pilot run, quantitative data were collected from students' and tutors' evaluation questionnaires using a 5-point Likert scale to explore their experiences in CLCs. Both questionnaires consist of eight questions which covered content, concept, user 
interface, learning preferences, and facilitation. Both questionnaires were developed based on a study by Ozkan and Koseler [15] on the multi-dimensional students' evaluation of e-learning system in higher education and discussion among the tutors and stakeholders [16].

The questionnaires were administered for both pilot runs after the CLCs sessions. The analysis of the questionnaires was a simple descriptive data.

Qualitative data was obtained from the following sources: (1) students' and tutors' written responses to two open-ended questions in the evaluation questionnaires, which focused on the useful aspects of CLCs and the areas for improvement; (2) observation during the implementation of CLCs. This classroom observation was videotaped as supportive data to students' and tutors' questionnaires. All the qualitative data were collated and analysed.

\section{Action research cycle 1}

\section{1) Plan and act}

The first CLCs pilot run was carried out as described in the planning and acting phase of CLCs section.

\section{2) Observe}

Positive responses were received from both students' and tutors' questionnaires (Table 2). Students and tutors were satisfied with the content and the organization of the content (items 3 and 4) with more than $85 \%$ of the students and tutors agreeing that the content was well-organised and aligned with the objectives of the case. Also 83\% (15\% strongly agreed and 69\% agreed) of the students felt that CLCs session helped them learn the content better (item 1). Similarly, all the tutors (18\% strongly agreed and $82 \%$ agreed) felt the same way. In the students' open-ended questions, the majority described that the most useful part of CLCs is the real-case discussion. Some of the responses are shown below:

"I found that the utilization of a real-life scenario was particularly useful as it taught us things out of textbook scenarios."

"The discussion of the case with the rest of the group helped me find out the gaps in my knowledge and aided in my understanding of the topic."

Hence, it was not surprising that item no. 7 'CLCs

Table 2. Students' and Teachers' Feedback for the Evaluation Questionnaire

\begin{tabular}{|c|c|c|c|c|c|c|c|c|c|c|c|c|}
\hline \multirow{2}{*}{ Questionnaire } & \multicolumn{6}{|c|}{ Students' feedback $(\%)$} & \multicolumn{6}{|c|}{ Teachers' feedback $(\%)$} \\
\hline & SA & A & $\mathrm{N}$ & $\mathrm{D}$ & SD & NR & SA & A & $\mathrm{N}$ & $\mathrm{D}$ & SD & NR \\
\hline $\begin{array}{l}\text { I found that the collaborative learning case session helped } \\
\text { me (the students) learn the content better. }\end{array}$ & 15 & 69 & 83 & 14 & 2 & 1 & 18 & 82 & 100 & 0 & 0 & 0 \\
\hline $\begin{array}{l}\text { Having the pre-reading materials and viewing of the case } \\
\text { details before class helped me (the students) learn more } \\
\text { effectively during class }\end{array}$ & 12 & 63 & 76 & 22 & 2 & 1 & 55 & 45 & 100 & 0 & 0 & 0 \\
\hline I found the case was well-organised and easy to follow. & 15 & 74 & 89 & 11 & 0 & 0 & 36 & 64 & 100 & 0 & 0 & 0 \\
\hline $\begin{array}{l}\text { I found the content is aligned with the objectives of the } \\
\text { tutorial. }\end{array}$ & 24 & 73 & 97 & 3 & 0 & 0 & 36 & 64 & 100 & 0 & 0 & 0 \\
\hline The technology setup is user-friendly & 35 & 51 & 86 & 11 & 3 & 0 & 9 & 82 & 91 & 9 & 0 & 0 \\
\hline I found that the tutor's facilitation of the case was effective & 33 & 57 & 90 & 9 & 1 & 0 & 45 & 36 & 82 & 18 & 0 & 0 \\
\hline $\begin{array}{l}\text { Collaborative learning case session fosters interaction } \\
\text { between classmates }\end{array}$ & 32 & 57 & 89 & 11 & 0 & 0 & 18 & 73 & 91 & 9 & 0 & 0 \\
\hline $\begin{array}{l}\text { The duration of the entire tutorial session was sufficient } \\
\text { to cover content relevant to the topic }\end{array}$ & 22 & 70 & 92 & 6 & 1 & 1 & 18 & 36 & 55 & 36 & 0 & 9 \\
\hline
\end{tabular}

SA: Strongly agree, A: Agree, N: Neutral, D: Disagree, SD: Strongly disagree, NR: No response. 
session foster interaction between classmates' scored favourably in the students' and tutors' feedback. Nonetheless, there were three items which were conflicting between students' and tutors' responses. Although all tutors felt that the pre-reading materials helped the students to learn more effectively (55\% strongly agreed and $45 \%$ agreed), students thought otherwise (only 12\% strongly agreed and $63 \%$ agreed) due to the accessibility of the materials as indicated in students' open responses below:

"The pre-reading materials could have been made available in the form of $\mathrm{e}$-book $\cdots$ it is impractical to expect 300 students to borrow the same book from the library at the same time."

In terms of tutors' facilitation (item 6) and the duration of CLCs (item 8), more than $90 \%$ of the students chose to either strongly agree or agree. Nevertheless, few problems in relation to tutors' facilitation were highlighted based on students' feedback and observation.

\footnotetext{
"'The tutor could guide the students' less, and let them discover the answers by themselves." (Student feedback) " The tutors were also very unprepared and they were unaware of what information was made available in the case details given to the students." (Student feedback) "I observed that tutors were not familiar with the pacing and organizing the session, they tend to give "model answer' rather than invoking a reflective style of teaching.*After a while, the session degenerated into a question and answer session, which is not collaborative learning." (Observers note)
}

On the other hand, some tutors found the facilitation was not that effective and duration was certainly not being productively utilised during the CLCs session. This was perhaps due to the use of technology during the CLCs session, which has affected the delivery as shown in the tutors' feedback:

"....had issues as the class progressed due to lagging in wireless connectivity $\cdots$ Have at least two tutors on hand, as we toggle between turns, one addresses the class and the other operates the PC."

"The format of giving time to discuss each part among themselves was disruptive $\cdots$ there were groups took longer time than others and time wasted waiting for every group to catch up. Time also wasted on doing 10 questions before starting."

This could be triangulated with students' data as some students mentioned the same comments in their open responses:

"In technical difficulties, too much time was spent on fixing and trying to get the screen to work."

"There were some technical problems that took quite a bit of the lesson to resolve."

Clearly, technological tools were not that helpful in the first cycle of CLCs. In fact, some students and tutors raised that the technological tools were distracting the whole learning process.

"I think such methods of teaching are a massive waste of time and resources $\cdots$ Using computer was very inefficient." (Student's feedback)

"The padlet wall hardly utilised by the students." (Tutor's feedback)

In addition, students' and tutors' observation data also revealed that the use of technology impeded collaboration as shown in the following. 
"'More group discussion should be emphasised as many of us just spent time typing on our computers instead of discussing." (Student's feedback)

"'Most (students) were obsessed with typing answers to the questions rather than actual discussion; copying and pasting answers and even links to the answers instead of learning to paraphrase or assimilate." (Observers note)

Apart from giving us an insight of the evaluation questionnaire, the open-ended questions also highlighted certain issues for improvement, such as group arrangement.

"Maybe it would be better to stick with our clinical group. This is because we know our clinical group mates' working style better and more comfortable discussing." (Student's feedback)

"The splitting of clinical groups. As we are not familiar with everyone in the team." (Student's feedback)

\section{3) Reflect}

Generally, the feedback from the tutors and students were encouraging. However, the technology tools used during the sessions turned out to distract rather than enhance collaboration and learning. This observation was consistent with what others had found [8]. This issue had to be resolved in the next cycle with proper integration. Similarly, pre-reading materials did not assist much in CLCs session due to its lack of accessibility. Giving training to tutors on how to facilitate group discussion was also important as some tutors tended to use a more didactic approach instead of scaffolding learning for the students. Although our initial idea of having a different group arrangement was to allow students to expand their interaction beyond their own clinical groups, it did not work out well as pointed out by Belbin [17] that forming a stable group takes time. Hence, students were having difficulty and trying to figure out their mates' working styles in the first cycle of CLCs discussion in addition to trying to solve a case in a given time frame.

\section{Action research cycle 2}

\section{1) Plan}

(1) Decrease the use of different platforms and replace with a more user-friendly platform which is 'Learning Catalytics' (Fig. 4). (2) Emphasise the role of tutors and the importance of scaffolding learning during CLCs

Fig. 4. An Example of Learning Catalytics Interface

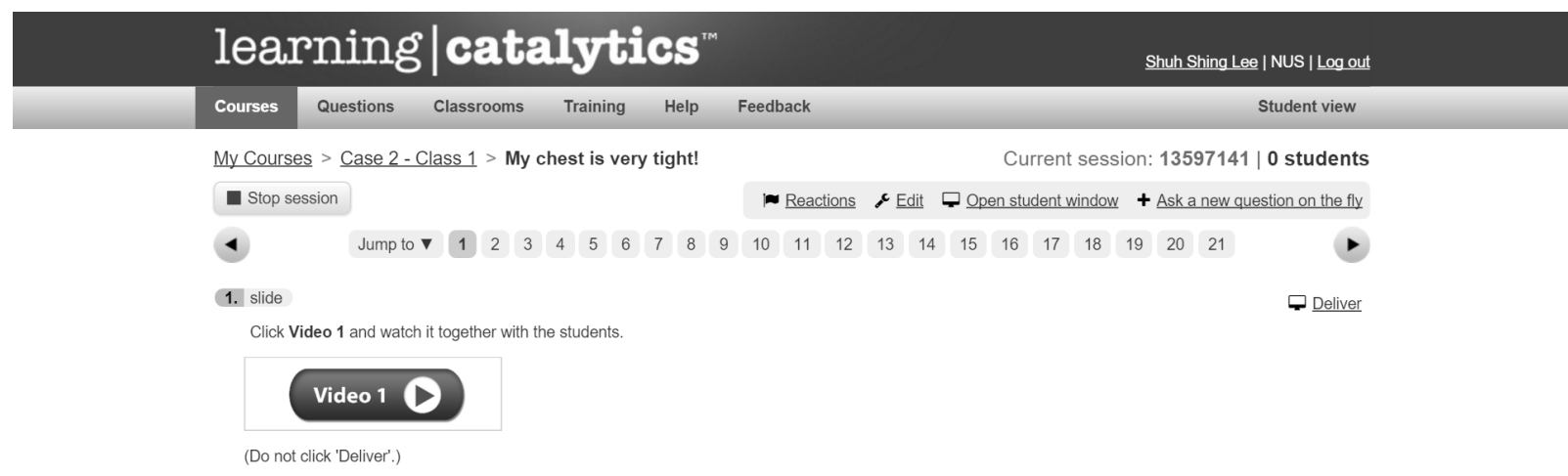


training session. (3) Arrange for two tutors (one basic science tutor and one clinical tutor) in each classroom. (4) Arrange students according to their clinical groupings instead of forming new groups. (5) Replacing "bring your own device' with iPads provided for each group. (6) Make pre-reading materials more accessible for students. (7) Seat arrangement in a round table instead of rectangular form. (8) Students' and tutors' evaluation questionnaire were amended to be more focused. Additional questions related to technology usage were added.

2) Act

Similar implementation processes of CLCs were carried out. The three technological tools utilised in cycle 1 were replaced by just one platform which is 'Learning Catalytics' (Fig. 4). Pre-reading materials were made more accessible for students. In order to promote discussion, we replaced 'bring your own device' by providing iPads for each group. Tutor training was carried out with more emphasis on their roles and scaffolding during CLCs session.

\section{3) Observation}

In the second cycle, there were slight changes in students' and tutors' questionnaires. All of the questions in the evaluation questionnaire in cycle 1 remained with additional questions related to technological tools (Table 3).

\begin{tabular}{|c|c|c|c|c|c|c|}
\hline & SA & A & $\mathrm{N}$ & $\mathrm{D}$ & SD & NR \\
\hline \multicolumn{7}{|l|}{ Students' feedback } \\
\hline The session reinforced my learning for various concepts covered in the case. & 31 & 58 & 9 & 2 & 0 & 0 \\
\hline Going through the pre-reading materials helped me better prepare for the session. & 18 & 63 & 17 & 2 & 0 & 0 \\
\hline I found the case was well-organised and easy to follow. & 40 & 55 & 4 & 1 & 0 & 0 \\
\hline I found that the tutor's facilitation of the case was effective. & 38 & 48 & 10 & 4 & 0 & 0 \\
\hline The duration of the tutorial was just nice for all the teaching and learning activities. & 26 & 44 & 15 & 13 & 2 & 0 \\
\hline Overall, I enjoyed the session and I look forward to the next one. & 29 & 47 & 15 & 8 & 1 & 0 \\
\hline \multicolumn{7}{|l|}{ Technology usage } \\
\hline Answering questions using 'Learning Catalytics' & 23 & 56 & 15 & 5 & 1 & 0 \\
\hline Sitting around round tables with my classmates & 44 & 47 & 6 & 3 & 0 & 0 \\
\hline TV for screen sharing within the group & 42 & 47 & 8 & 2 & 1 & 0 \\
\hline iPad provided for each group & 33 & 54 & 7 & 5 & 1 & 0 \\
\hline Whiteboard & 13 & 27 & 31 & 19 & 10 & 2 \\
\hline \multicolumn{7}{|l|}{ Tutors' feedback } \\
\hline The tutor's resources helped me prepare and teach more effectively. & 38 & 56 & 0 & 6 & 0 & 0 \\
\hline The case was well-organised and easy to follow. & 38 & 62 & 0 & 0 & 0 & 0 \\
\hline The content is aligned with the objectives of the tutorial. & 31 & 69 & 0 & 0 & 0 & 0 \\
\hline $\begin{array}{l}\text { The Collaborative Learning Caseteaching method is more interactive and engaging } \\
\text { for the students, compared to a traditional lecture. }\end{array}$ & 19 & 63 & 12 & 6 & 0 & 0 \\
\hline $\begin{array}{l}\text { Overall, I enjoyed facilitating the session and I look forward to participating in this } \\
\text { format of teaching in the future. }\end{array}$ & 31 & 50 & 19 & 0 & 0 & 0 \\
\hline \multicolumn{7}{|l|}{ Technology usage } \\
\hline Delivering questions using 'Learning Catalytics' & 31 & 44 & 19 & 6 & 0 & 0 \\
\hline Sitting students around round tables & 31 & 44 & 25 & 0 & 0 & 0 \\
\hline TV for screen sharing within each group & 25 & 50 & 25 & 0 & 0 & 0 \\
\hline iPad provided for each group & 31 & 50 & 19 & 0 & 0 & 0 \\
\hline Dual monitors & 27 & 40 & 33 & 0 & 0 & 0 \\
\hline Whiteboard & 19 & 25 & 25 & 25 & 6 & 0 \\
\hline
\end{tabular}

Data are presented as \%.

SA: Strongly agree, A: Agree, N: Neutral, D: Disagree, SD: Strongly disagree, NR: No response. 
Overall, students and tutors were satisfied with the content and organization of the content. Students also felt that the pre-reading materials were useful in preparing them for the session with only $2 \%$ of them disagreed with the statement. Tutors' facilitation was well-received by the students which were indicated in their evaluation questionnaires as well as their openended responses as follows (Table 2):

"It was interactive and informative with the presence of two tutors."

"Instructor very engaging."

Students also felt that the session has reinforced their learning which is aligned with their open-ended response.

"Flow of the tutorial, everything linked-up, allowed us to apply what we learned."

"It connects many aspects of cardiovascular physiology."

However, students were not satisfied with the duration of the session. The majority of them commented the session was too long in their open response.

\section{"Session was too long, too many parts." \\ "Too lengthy, 1.5 hours will be enough."}

Tutors also raised concerns about the time allocated for discussion. Contrary to the students' comments, tutors felt that more time was required for discussion.

"This case has good opportunities to integrate physiology several systems. (It) was rather too rushed."

In terms of technology usage, some tutors and students liked it but others did not. Although not as many issues arose compared to the first cycle, the replacement of 'bring your own device' with iPads to discourage students from focusing on only typing and answering questions was not well-accepted:

"Some students were bored with only one iPad." (Tutor feedback)

"Provide more iPad." (Student feedback)

"Allow using own computer because it is very difficult to type on the iPad." (Student feedback)

\section{4) Reflection}

There were significant improvements in the second round of CLCs conducted, especially in the area of tutor facilitation, as fed back by the students. Students felt that the case discussion was very useful in applying the knowledge they have learned in basic sciences in a clinical scenario, with guidance from the tutors. Finding a suitable technology platform that could enhance students' collaboration in learning remains a challenge even though some changes were implemented. Knowing how to use hardware and software in an educational setting was still not adequate. Integration of technology for collaborative learning in the classroom involves multiple aspects such as selecting appropriate computer applications to meet the instructional needs of the learning event [12]. It is also important to understand the students' ability to work collaboratively in an information and communication technology environment and students-tutors interaction in a collaborative environment using technology. Restricting the students to having one device does not necessarily promote collaboration. Hence, freedom should be given to students to bring their own devices, but one student should be given the responsibility to key in the answer. Two tutors in the classroom are required in such setting to juggle with teaching and managing the technology 
simultaneously. In addition, two tutors (one clinical and one basic science) will be able to provide multiple aspects of medicine which complement each other. However, this can only be achieved if both tutors discussed the delivery approaches prior to the session. Last but not least, both tutors and students have to be trained on how to facilitate effectively and how to learn respectively in a technology-enhanced collaborative learning environment.

\section{Discussion}

The study showed that the implementation of CLCs at NUS Medicine had improved over the two cycles using action research method. The purpose of CLCs was to facilitate students in the preclinical phase of learning to integrate biomedical science knowledge through a pedagogical approach that encourages active learning involving scaffolding of knowledge and collaboration in a shared dialogic space. The effectiveness of this approach was highlighted in the students' feedback. Action research highlighted several areas for improvement such as the role of tutors, group arrangement and organisation, the use of technological applications, and time management.

In regard to tutors, action research showed that more effort was required to train the tutors so that they have a better understanding of the principles of CLCs and their role in CLCs as a facilitator of learning, not as the expert providing knowledge. Many of the tutors are experienced teachers, who have relied mainly on didactic forms of teaching. Faciliatation and scaffolding were relatively newer pedagogical principles, and they needed time and practice to know best to provide feedback and guidance and when they should take a step back to let the students work it out themselves. On the one hand, too much guidance and didactic teaching will stifle initiative and effort in constructing knowledge, on the other hand, insufficient guidance may result in students becoming lost and frustrated, their confusion leading to misconception $[18,19]$. Training tutors to facilitate well remains a challenge in faculty development. We also found that two tutors (one basic science and one clinician) were needed in this approach. The success of the partnership also depends on whether the tutors have had time to discuss their roles prior the session, and the chemistry between the tutors.

This research also reveals the importance of group management in a collaborative setting. The healthcare landscape has changed tremendously; operating in isolation is no longer desirable or safe in the delivery of patient care. Inculcating the value of teamwork is important and should begin as early as possible for medical students. It is challenging to form a highly functional team in the early years of training as the students are just getting to know each other in a non-practice environment. As demonstrated in our cycle 1 , being made to work with unfamiliar team members could be a hindrance to achieve the desired outcomes. This is consistent with a study by Yang [20] showing the importance of trust in an effective team. She argued that it will be difficult to form an effective team when team members do not have a history of interactions and prior knowledge of one another. Formation of an effective team takes time and involves five stages as proposed by Tuckman [21]-forming, storming, norming, performing, and transforming. Hence, adequate time is necessary for newly formed teams to progress through these stages. For the CLCs, given the constraint of time, using existing groupings (clinical group) was a possible workaround.

Another major challenge for the CLCs was to find suitable technology tools to enrich collaboration and 
enhance learning. Despite engaging in extensive background research to understand the how to integrate technology into classroom learning, based on different frameworks [22-25], certain constraints were highlighted by the students and tutors. This is beyond the first and the second barrier postulated by Ertmer et al. [12,13] and requires in-depth evaluation of the tools in promoting deep learning. McCain [26] elucidated, "the issue of foremost importance is to develop thinking skills in our students so that they will be able to utilize the power of technological tools to solve problems and do useful work". Although the principle of CLCs is aligned with McCain's statement, being able to select an appropriate tool to encourage collaboration and deeper learning is still scarce in the literature. Out study showed that technology can be a distractor and highlighted the importance of simplifying technology to enhance collaboration and learning.

There are some limitations to this study. The results of this study should be contextualised to medical education where the medical students have been selected via a rigorous process that valued attributes like good communication skills, team skills, etc. Hence, the students were generally more active in participating in classroom activities. The implementation of CLCs pilot runs was embedded in their formal learning schedule on top of the different types of teaching and learning sessions (such as lectures, tutorials, and practical and simulation sessions). Fatigue arising from attending different sessions could have indirectly affected their evaluation. Finally, the students were not involved in the questionnaire development process since it was based on findings in a literature search and expert faculty involvement. We acknowledge that context may affect the use of the questionnaire; hence, we included open-ended questions to obtain data which may not have been captured by the items on the Likert scale.
In conclusion, the main purpose of CLCs implementation was to assist students to develop the linkages between basic medical sciences and clinical application. We piloted the learning event and two cycles of action research to help us create a better learning environment for the students. Improvements in the physical environment, such as technology support, were made hand in hand with enhanced faculty development in regard to the use of technology, time management, and facilitation skills, to create a better learning environment. The action research described in this study can be a model for others who are embarking on similar efforts to innovate new learning encounters that involve active collaboration among students.

\section{ORCID:}

Shuh Shing Lee: https://orcid.org/0000-0002-6760-1340; Shing Chuan Hooi: https://orcid.org/0000-0003-3249-903X; Terry Pan: https://orcid.org/0000-0001-6607-1520; Chong Hui Ann Fong: https://orcid.org/0000-0002-9300-5307; Dujeepa D. Samarasekera: https://orcid.org/0000-0002-6916-6741 Acknowledgements: The authors thank the Educational Technology team, Yong Loo Lin School of Medicine in providing the technological input and support in CLCs. The authors thank the Year 1 students in taking part in this pilot test.

Funding: No funding for this project.

Conflicts of interest: No potential conflict of interest relevant to this article was reported.

Author contributions: Conception or design of the work: DDS, SSL, TP, SCH; data collection, data analysis, and interpretation: DDS, SSL, TP, SCH; and drafting the article, critical revision of the article, and final approval of the version to be published: DDS, SSL, TP, SCH, CHAF. 


\section{References}

1. Flexner A. Medical education in the United States and Canada. Washington, USA: Science and Health Publications; 1910.

2. World Health Organization. Reorientation of medical education: guidelines for developing national plans for action. http://apps.searo.who.int/pds_docs/B0086.pdf. Published 1991. Accessed May 11, 2016.

3. Zou L, King A, Soman S, et al. Medical students' preferences in radiology education a comparison between the Socratic and didactic methods utilizing PowerPoint features in radiology education. Acad Radiol. 2011; $18(2): 253-256$.

4. World Health Organization. Global health workforce shortage to reach 12.9 million in coming decades. http:// www.who.int/mediacentre/news/releases/2013/health-wor kforce-shortage/en/. Published 2013. Accessed May 11, 2016.

5. Barrow M, McKimm J, Samarasekera DD. Strategies for planning and designing medical curricula and clinical teaching. South East Asian J Med Educ. 2010;4(1):2-8.

6. Gwee MC. Problem-based learning: a strategic learning system design for the education of healthcare professionals in the 21st century. Kaohsiung J Med Sci. 2009;25(5):231-239.

7. Kirschner PA, Sweller J, Clark RE. Why minimal guidance during instruction does not work: an analysis of the failure of constructivist, discovery, problem-based, experiential, and inquiry-based teaching. Educ Psychol. 2006;4l(2):75-86.

8. Kershner R, Mercer N, Warwick P, Staarman JK. Can the interactive whiteboard support young children's collaborative communication and thinking in classroom science activities? Int J Comput Support Collab Learn. 2010;5(4):359-383.
9. Warwick P, Mercer N, Kershner R, Staarman JK. In the mind and in the technology: the vicarious presence of the teacher in pupil's learning of science in collaborative group activity at the interactive whiteboard. Comput Educ. 2010;55(1):350-362.

10. Mueller J, Wood E, Willoughby T, Ross C, Specht J. Identifying discriminating variables between teachers who fully integrate computers and teachers with limited integration. Comput Educ. 2008;51(4):1523-1537.

11. Tondeur J, van Braak J, Valcke M. Towards a typology of computer use in primary education. J Comput Assist Learn. 2007;23(3):197-206.

12. Ertmer PA, Ottenbreit-Leftwich AT. Teacher technology change: how knowledge, confidence, beliefs, and culture intersect. J Res Technol Educ. 2010;42(3):255-284.

13. Ertmer PA, Ottenbreit-Leftwich AT, Sadik O, Sendurur E, Sendurur P. Teacher beliefs and technology integration practices: a critical relationship. Comput Educ. 2012;59(2):423-435.

14. Kemmis S, McTaggart R. Participatory action research. In: Denzin NK, Lincoln YS, eds. Handbook of Qualitative Research. 2nd ed. Thousand Oaks, USA: Sage; 2000:567-606.

15. Ozkan S, Koseler R. Multi-dimensional students' evaluation of e-learning systems in the higher education context: an empirical investigation. Comput Educ. 2009; 53(4):1285-1296.

16. Hodgson Y, Benson R, Brack C. Using action research to improve student engagement in a peer-assisted learning programme. Educ Action Res. 2013;21(3):359-375.

17. Belbin RM. Management teams: why they succeed or fail. 2nd ed. Oxford, UK: Elsevier Butterworth-Heinemann; 2004.

18. Hardiman PT, Pollatsek A, Well AD. Learning to understand the balance beam. Cogn Instr. 1986;3(1): 63-86.

19. Brown A, Campione J. Guided discovery in a community 
of learners. In: McGilly $\mathrm{K}$, ed. Classroom Lessons: Integrating Cognitive Theory and Classroom Practice. Cambridge, USA: MIT Press; 1994:229-270.

20. Yang I. What makes an effective team?: the role of trust (dis)confirmation in team development. Eur Manag J. 2014;32(6):858-869.

21. Tuckman BW. Developmental sequence in small groups. Psychol Bull. 1965;63(6):384-399.

22. Angeli C, Valanides N. Preservice elementary teachers as information and communication technology designers: an instructional systems design model based on an expanded view of pedagogical content knowledge. J Comput Assist Learn. 2005;21(4):292-302.
23. Koehler M, Mishra P. What is technological pedagogical content knowledge (TPACK)? Contemp Issues Technol Teach Educ. 2009;9(1):60-70.

24. Margerum-Leys J, Marx RW. Teacher knowledge of educational technology: a case study of student/mentor teacher pairs. J Educ Comput Res. 2002;26(4):427-462.

25. Niess ML. Preparing teachers to teach science and mathematics with technology: developing a technology pedagogical content knowledge. Teach Teach Educ. 2005;21(5):509-523.

26. McCain $\mathrm{T}$. Teaching for tomorrow: teaching content and problem-solving skills. Thousand Oaks, USA: Corwin; 2005. 